\title{
A Study on the Potential of Electricity Generation from Cassava Rhizome in Eastern Region Area of Thailand
}

\author{
Mananya Saengsaior ${ }^{1, *}$, Weerachai Arjharn ${ }^{1}$, Pansa Liplab $^{2}$, Thipsupin Hinsui ${ }^{2}$ \\ ${ }^{1}$ School of Agricultural Engineering, Institute of Engineering, in Suranaree University of Technology, Thailand \\ ${ }^{2}$ Center of Excellence in Biomass, Suranaree University of Technology, Thailand
}

\begin{abstract}
In this study, the objective was to investigate the quality and suitability of processing, improving the quality of waste biomass from cassava growing in east region area of Thailand. There is a method for studying quantitative data from the land use database together with the geographic information system. And the physical quality and chemical properties of cassava rhizomes have been studied from the analysis of cassava rhizome samples in the laboratory. The results of the study found that east region area of Thailand is the biggest area for cassava cultivation in Thailand. Crop residual ratio (CRR) of cassava rhizome was 0.112 with the total remaining amount of $636,003.35$ tons/year $(\sim 53.40 \%$ wb moisture content and 8.19 $\mathrm{MJ} / \mathrm{kg}$ heating value). It was estimated that the total amount of cassava rhizome ready to use as biomass with chip/pellet grade at moisture content of $\sim 10.17 \% \mathrm{wb}$. and heating value of $\sim 12.50 \mathrm{MJ} / \mathrm{Kg}$ is 89,040 tons/year, having equivalent energy of $1,113.01 \mathrm{GJ}$ or $26.58 \mathrm{ktoe}$. This could be used to produce electricity of $61.8 \mathrm{GWh}$ or used to supply power plants with total capacity of $8.8 \mathrm{MW}$.
\end{abstract}

\section{Introduction}

Cassava is one of the important agricultural crops in Thailand, and it is among the five agricultural produces' export. According to the Office of Agricultural Economics. Cassava or tapioca is an important agricultural commodity in Thailand. Also, majority of Thai farmers own their farm land spread over rural areas. The reason is that nature of cassava can be harvested all over the year and can be grown in most suitable lands in Thailand. In 2001, Thailand's agricultural trade ranked 10 th in the world, and that accounted for $11.7 \%$ of agricultural exports [1] Thus, the Thai government policy was to promote exporting agricultural products, which the international trade data of Thailand in 2008. Thailand is the third-largest producer of Cassava in the World [1,2]. In 2018, 24 million tons of processed cassava pellets were produced, with an approximate value of 44 percent of all cassava grown in Thailand.

However, there were some cassava wastes which could be used in the manufacturing of other consumers' products. Though many people do not consider the numerous benefits from cassava rhizome, and one of these benefits is the amount of energy that could be generated, which was found out to be an equivalent of single firewood [3]. In fact, it is classified as a biomass, for its unique potential for electricity generation.

Generally, the cassava plant is composed of root, top/leaf, stem, and rhizome Cassava roots are processed into pellets, chips and starch, mainly used as raw materials for several industrial and commercial purposes such as food, beverage, sweetener, textile, paper, glue and ethanol [4]. There are many routes to convert cassava waste for energy [5-10]. Biomass is accounted for a major fraction in renewable energy in Thailand. The eastern region of Thailand has a total area of $22.81 \times 10^{6}$ rai, which is agricultural cultivated area approximately $12.88 \times 10^{6}$ rai, representing 56.5 percent of the total Eastern region. The cultivated area for cassava is $1.5 \times 10^{6}$ rai [11]. There are plenty of cassava residues, especially its rhizome, left unused in the field after harvesting. Thus, they show potential for use as a raw material in energy production. In addition, it was reported that the power plants in this region are facing a problem on raw material in terms of uncertainty and insufficient amount. Thus, cassava rhizome is promising, using as alternative raw material for the power plant. However, to promote the use of cassava rhizome it is important to know the fuel characteristics, potential along with its distribution in the region.

In this research, the main objective is to study potential of cassava rhizome using as raw material for energy production in terms of quantity and quality. The results can explore the suitability of cassava rhizome for energy production in the eastern region of Thailand.

\section{Methodology}

Our study on the potential generation of electricity from cassava rhizomes in the eastern region of Thailand is divided into 2 sections, which are: The survey and analysis of the quantitative data (quantity), and qualitative (quality) of the cassava stalks as a renewable energy through biomass.

* Corresponding author: Nanya_Sangsaior@gmail.com 


\subsection{Data and Survey}

The survey and analysis of quantitative data on cassava rhizomes as a form of renewable energy focus on the followings:

- Information on cassava, and its uses for potential and quantitative data analysis.

- The natural quality of cassava rhizome in the eastern Thailand.

- And Information on cassava planting area, at the district and provincial levels of Thailand's eastern region.

- Information from the Agricultural Economic Development Agency on the average yield of cassava per ton per rai, of each province.

- Spatial data sets on the four-dimensional extent and scope of government (Sharp file and Digital file) from the Department of Land Development.

\subsection{Data analysis}

Quantitative data analysis (quantity) of cassava rhizomes for the study of spatial energy potential:

- Biomass Yield Ratio Crop Residue Ratios: (CRR) is the amount of biomass for energy generation without residue. - Energy potential of biomass (kiloton per oil equivalent; toe).

- Details on area, quantity of existing biomass raw materials, and the estimation of potential to commerce acquisition for biomass feedstock.

- Data analysis on the quality of cassava rhizomes:

- Physical properties of biomass fuel such as: size, size distribution, moisture content, and appearance density.

- Proximate analysis of biomass fuel such as: moisture, ash, volatile matter, and fixed carbon. Analysis was performed according to ASTM E 1617-94 [12] and ASTM E 1755-01 [13], while according to ASTM D 2015 [14], a bomb calorimeter was adopted for different heating values.

- The ultimate analysis of biomass fuels such as: C, H, N, $\mathrm{S}$, and $\mathrm{O}$ was conducted, moreover, elemental analyses of carbon $(\mathrm{C})$, hydrogen $(\mathrm{H})$, and nitrogen $(\mathrm{N})$ were done with the use of a PerkinElmer 2400 CHNS Elemental Analyzer. The sulfur (S) content was determined by the use of a plasma spectrometry, while that of optical analysis was carried with a Sector ICP-OES spectrometer as established by titration according to [15].

\section{Results}

\subsection{Quantity properties (quantity) of cassava rhizomes}

The cassava is cultivated in the tropics to produce roots, used primarily for human consumption but also for animal feed and the extraction of starch. Cassava plants have a high biomass yield under good environmental conditions and a great ability to adapt to environments with biotic and abiotic stresses, such as poor-fertility or water-stressed soils where other cultures are not feasible. The aerial part of the plant consists of thick and thin stalks, petioles and leaves, and the underground part consists of roots and the seed stem and cassava stalks that were cut into approximately $200 \mathrm{~mm}$-long sections and planted to reproduce the plant asexually, and after it grows it looks like woody biomass. The structure of the plant is shown in Fig. 1. Harvesting usually involves cutting the stalks, uprooting the plant from the soil and removing the roots. While the first two operations can be done by mechanical equipment, the seed stem and roots are separated manually as there is no mechanical equipment available to carry out this operation. After all the process of harvest, about half of the biomass produced is abandoned in the fields.

The cassava cultivated area in the eastern region of Thailand is 1,529,576.24, and the average value of fresh cassava rhizomes is about $359 \mathrm{~kg} / \mathrm{rai}$. In addition, the ratio of cassava rhizome per (CRR) is approximately 0.12 as displayed in Table 1, while the number of the remaining fresh cassava rhizomes amounts to 636,003 tons/year with humidity of about $53.40 \% \mathrm{wb}$, and heating value of $12.50 \mathrm{MJ} / \mathrm{kg}$ as shown in Table 2 .

Table 1. Crop residual ratio: CRR

\begin{tabular}{lccc}
\hline Biomass & $\begin{array}{c}\text { Fresh } \\
\text { cassava } \\
\text { weight } \\
(\mathrm{kg} / \mathrm{rai})\end{array}$ & $\begin{array}{c}\text { Fresh } \\
\text { cassava } \\
\text { rhizomes } \\
\text { weight } \\
(\mathrm{kg} / \mathrm{rai})\end{array}$ & $\begin{array}{c}\text { Crop residual } \\
\text { ratio: } \\
(\mathrm{CRR})\end{array}$ \\
\hline $\begin{array}{l}\text { cassava } \\
\text { rhizomes }\end{array}$ & $8,757,938.2$ & $636,003.35$ & 0.112 \\
\hline
\end{tabular}

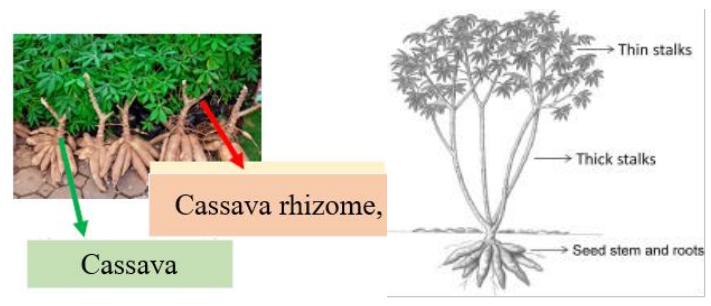

Fig.1. Cassava rhizomes

Table 2. Residual cassava rhizome in the eastern region at Thailand

\begin{tabular}{|c|c|c|c|c|c|c|}
\hline \multirow[b]{2}{*}{ province } & \multirow{2}{*}{$\begin{array}{c}1^{1 *} \text { Average } \\
\text { yield } \\
\text { (Ton/ Year) }\end{array}$} & \multicolumn{2}{|c|}{ Cultivation area } & \multirow{2}{*}{$\begin{array}{c}4^{*} \text { Cassava } \\
\text { product } \\
\text { (Ton/Year) }\end{array}$} & \multirow{2}{*}{$\begin{array}{c}{ }^{5^{*}} \text { crop } \\
\text { residual } \\
\text { ratio:CRR }\end{array}$} & \multirow{2}{*}{$\begin{array}{c}{ }^{6^{*} \text { Cassava rhizomes }} \\
\text { (Ton/Year) }\end{array}$} \\
\hline & & $2^{*}\left(\mathrm{Km}^{2}\right)$ & $3^{*}$ (rai) & & & \\
\hline Chanthaburi & 3.24 & $125,013,295.53$ & $78,133.31$ & $253,151.92$ & 0.112 & $30,125.08$ \\
\hline Rayong & 4.40 & $130,864,317.17$ & $81,790.20$ & $359,876.87$ & 0.112 & $42,825.35$ \\
\hline Chon Buri & 4.02 & $400,684,547.12$ & $250,427.84$ & $1,007,471.21$ & 0.112 & $119,889.07$ \\
\hline Sa Kaeo & 3.29 & $965,895,178.60$ & $603,684.49$ & $1,986,926.87$ & 0.112 & $236,444.30$ \\
\hline
\end{tabular}




\begin{tabular}{lcccccc} 
Chachoengsao & 3.38 & $395,434,852.24$ & $247,146.78$ & $835,603.27$ & 0.112 & $99,436.79$ \\
Prachin Buri & 3.36 & $429,419,720.39$ & 268387.32 & $901,513.03$ & 0.112 & $107,280.05$ \\
Tart & 3.62 & $10,068.14$ & 6.29 & 22.75 & 0.112 & 2.71 \\
Total & - & - & $1,529,576.24$ & $253,151.92$ & - & $636,003.35$ \\
\hline
\end{tabular}

Table 3. Residual cassava rhizome in the eastern region at Thailand

\begin{tabular}{lccc}
\hline province & $\begin{array}{c}\text { Cultivation area } \\
\text { (rai) }\end{array}$ & $\begin{array}{c}\text { Average yield } \\
\text { (Ton/ Year) }\end{array}$ & $\begin{array}{c}\text { Cassava rhizomes } \\
\text { (CRR) }\end{array}$ \\
\hline Chanthaburi & $78,133.31$ & 3.24 & $30,125.08$ \\
Rayong & $81,790.20$ & 4.40 & $42,825.35$ \\
Chon Buri & $250,427.84$ & 4.02 & $119,889.07$ \\
Sa Kaeo & $603,684.49$ & 3.29 & $236,444.30$ \\
Chachoengsao & $247,146.78$ & 3.38 & $99,436.79$ \\
Prachin Buri & 268387.32 & 3.36 & $107,280.05$ \\
Tart & 6.29 & 3.62 & 2.71 \\
Total & $1,529,576.24$ & - & $636,003.35$ \\
\hline
\end{tabular}

The results of our study as shown in Table 2 and Table 3 reveal the prospect of electricity generation from cassava cultivation through biomass processing technique in the eastern region of Thailand. This tendency for energy generation is publicized and substantiated by the statistical results of 1,529,576.24 rai cassava cultivated areas of the eastern's seven provinces. An average yield of 3.59 tons of cassava per rai, and the remaining cassava rhizomes are $636,003.35$ tons per year. Furthermore, the density's range of cassava stalks as a potential raw material for biomass is divided into 5: density fewer than 1,000 tons, density range of 1000 3000 ton, 3000-5000 tons, 5,000 - 10,000 tons per year, and a density of more than 10,000 tons per year. The research on cassava stalks in the eastern region is presented in Figure 2, whereas, the spatial density of cassava rhizomes as displayed in Figure 3 reveals the richness of Wang province over its neighborhood., Sa Kaeo Province and Chachoengsao province (red zone) have more than 10,000 tons of cassava rhizomes per year.

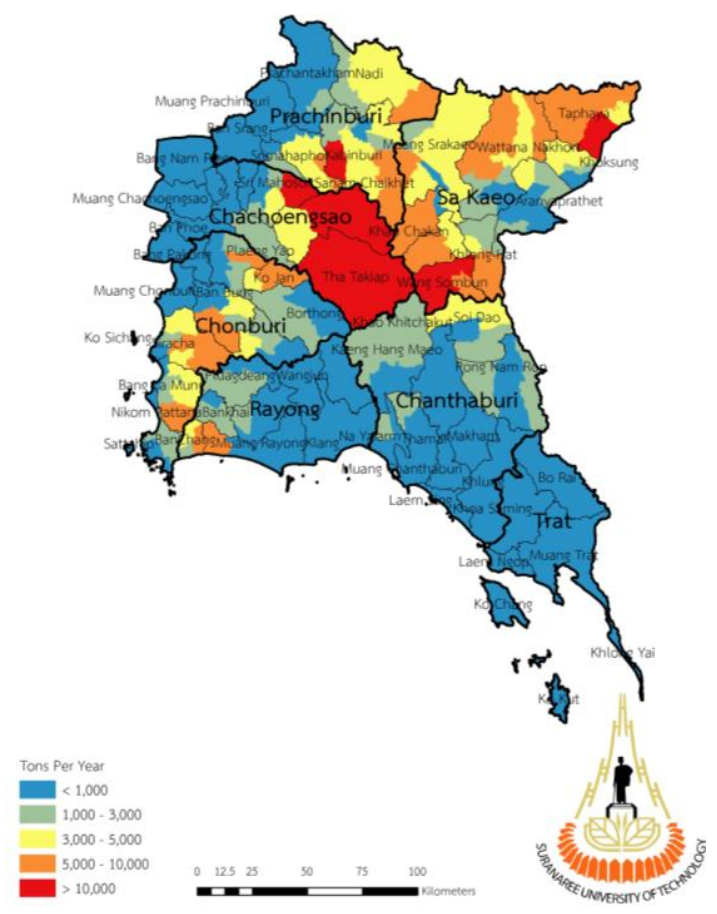

Fig.2. Potential of cassava rhizomes in the eastern region

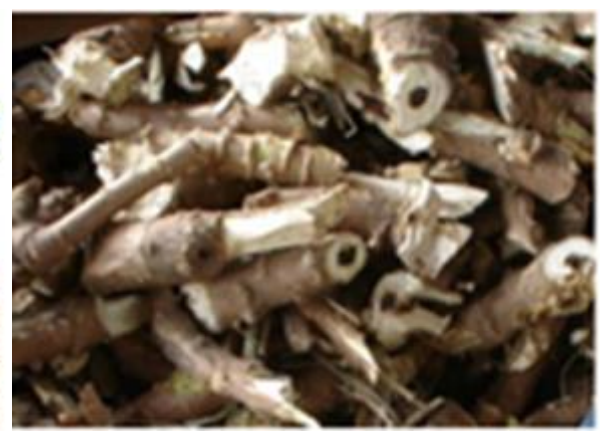

Fig. 3. The potential for energy production

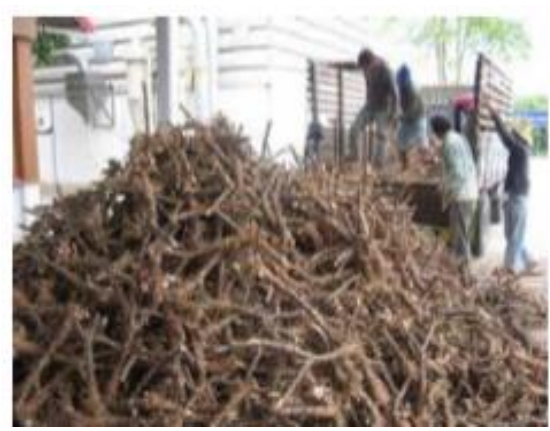

The sample analysis on the quality of cassava rhizomes

\subsection{Quality properties (quality) of cassava rhizomes}

revealed that the qualitative and qualitative analyses of cassava roots could be used in the production of renewable energy. The physical properties of biomass 
fuel such as: size, size distribution, moisture content), appearance densities were also duly investigated and examined. Lastly, the Proximate and Ultimate analyses were carried out.

The physical properties of cassava rhizomes such as; size, density, and moisture content of (40-70\%) are presented in Table 4. These irregular sizes and shapes depend on species, and different techniques of harvesting (machine and human labor). Most biomass fuels are of low-densities with replica features; nonetheless, there are some exceptions in the commercialized biomass fuels.

Table 4. Crop residual ratio: CRR

\begin{tabular}{lccc}
\hline $\begin{array}{l}\text { Types of } \\
\text { biomass }\end{array}$ & $\begin{array}{c}\text { moisture } \\
(\% \mathrm{wb})\end{array}$ & $\begin{array}{l}\text { density } \\
\left(\mathrm{kg} / \mathrm{m}^{3}\right)\end{array}$ & generalization \\
\hline $\begin{array}{l}\text { Cassava } \\
\text { rhizome }\end{array}$ & 53.40 & 193 & $\begin{array}{l}\text { Sectional diameter of } \\
1-2 \text { inches of the stem } \\
\text { end. }\end{array}$ \\
\hline
\end{tabular}

An exclusive property of biomass elements, which is the Proximate Value was highly observed and thoroughly scrutinized in our study. Though, the ratio of Moisture Content, amount of Volatile Matter of Fixed Carbon, Ash Content and the ASTM standard method of analysis in the selection process were appropriately considered. The heat experiment adopted the use of cassava roots as the main fuel in the analysis of heat, and humidity relationship. From the analysis of biomass moisture, it was concluded that the heating value of cassava rhizomes as an alternate source of fuel was inversely proportional to the cassava roots' humidity. It was discovered that the cassava roots of moisture content $53.40 \%$ has a low calorific value (LHV) of $8.19 \mathrm{MJ} / \mathrm{kg}$, this value serves as a threshold value for generating electricity or heat energy. Nevertheless, if the moisture content of the cassava rhizomes has humidity value of $4.66 \%$, the heating value of fuel would be significantly by $14.591 \mathrm{MJ} / \mathrm{kg}$ as shown in the Table. 5 and also Table 6.

Table 5 Chemical properties of cassava rhizomes

\begin{tabular}{|c|c|c|c|c|c|}
\hline \multicolumn{6}{|l|}{ Proximate Value } \\
\hline \multirow{2}{*}{$\begin{array}{c}\text { Moisture Content } \\
(\%)\end{array}$} & \multicolumn{3}{|c|}{ Proximate Value } & \multicolumn{2}{|c|}{ Heating Value } \\
\hline & $\begin{array}{c}\text { Volatile Matter } \\
(\%)\end{array}$ & $\begin{array}{c}\text { Ash Content } \\
(\%)\end{array}$ & $\begin{array}{l}\text { Fixed Carbon } \\
(\%)\end{array}$ & $\begin{array}{c}\text { Volatile Matter } \\
(\%)\end{array}$ & $\begin{array}{c}\text { Ash Content } \\
(\%)\end{array}$ \\
\hline 4.66 & 80.00 & 2.73 & 13.00 & 8,190 & 14,591 \\
\hline \multicolumn{6}{|l|}{ Ultimate Value } \\
\hline \multicolumn{6}{|c|}{ The proportion of the elements (percent). } \\
\hline $\mathrm{C}$ & $\mathrm{H}$ & & $\mathrm{N}$ & $\mathrm{S}$ & $\mathrm{O}$ \\
\hline 46.12 & 7.55 & & 1.13 & 0.03 & 54.83 \\
\hline
\end{tabular}

Table 5, depicts the information of our proposed source of energy from the agricultural wastes of Thai's cassava plantations. Their thermochemical properties, proximate, ultimate, structural, inorganic matter, heating values, and thermo gravimetric analyses are determined, and rigorously examined in this study. Our results illustrate that these wastes have high volatile contents (of $80 \%$, on dry basis), and contain $46.12 \%$ of carbon that is slightly different from those of [16], which portrays $\mathrm{C}$ content of about $51 \%, 1.13 \%$ hydrogen ,54.83\% of oxygen, and a biomass high heating value (HHV) of approximately $14.159 \mathrm{MJkg}^{-1}$.

\subsection{The potential for energy production}

In addition, our results indicate that cassava wastes possess high volatility tendency and very low nitrogen with a medium heating value. Outcomes form our study indicate that an environmentally friendly and nonthreatening bio-fuel could be produced via thermochemical conversion process that is identical to that of fast pyrolysis.

Likewise, Dioxins could be formed from all combustion processes, when organic carbon and oxygen are present [17], and these Dioxins are considered to be very hazardous to human health. Moreover, an acid rain is a severe problem, due to the burning of fuel with high sulphur content. But cassava wastes are environmentally friendly, due to its low $\mathrm{S}$ content of about $0.3-0.2 \%$ respectively. The use of cassava wastes prevents the emission of dioxins, $\mathrm{HCl}, \mathrm{SOx}$, and other harmful particles as stated in [18]. Hot corrosion of super heaters could also be enhanced by different surfaces, it increases the foul smells from the heat transfer of chlorine due to the formation of chloride, and sulphates, which vaporize and condense on cold surfaces later on $[19,20]$. The small amounts of $\mathrm{S}$ and $\mathrm{Cl}$ embedded in the ash are caused by the high contents of alkali and earth-alkali metals. Therefore, reducing the quantities of $\mathrm{S}$ and $\mathrm{Cl}$ will completely eradicate the problems of acid rain [18].

Table 6. The potential for energy production

\begin{tabular}{|c|c|c|c|c|c|c|c|c|c|c|}
\hline \multirow[b]{2}{*}{ province } & \multirow[b]{2}{*}{$\begin{array}{l}\text { Cassava } \\
\text { rhizome } \\
\text { (Ton/Year) }\end{array}$} & \multicolumn{2}{|c|}{ Loss rate } & \multirow[b]{2}{*}{$\begin{array}{l}\text { heating } \\
\text { Value } \\
\mathrm{MJ} / \mathrm{kg}\end{array}$} & \multicolumn{6}{|c|}{ Potential energy } \\
\hline & & $\begin{array}{c}\text { Dehumidification } \\
80 \% \\
\text { (Ton/Year) }\end{array}$ & $\begin{array}{c}\text { Manufacturing } \\
30 \% \\
\text { (Ton/Year) }\end{array}$ & & $\begin{array}{l}\text { Biomass } \\
\text { Energy } \\
\text { potoentail } \\
\text { (GJ/Year) }\end{array}$ & $\begin{array}{c}\text { Energy } \\
\text { potoentail } \\
\text { (Ton of Oil } \\
\text { Equivalent, } \\
\text { toe) }\end{array}$ & $\begin{array}{c}\text { Dehumidification } \\
80 \% \\
\text { (Ton/Year) }\end{array}$ & $\begin{array}{c}\text { Manufacturing } \\
30 \% \\
\text { (Ton/Year) }\end{array}$ & $\begin{array}{l}\text { Power } \\
\text { Plant } \\
\text { capacity } \\
\text { (MW) }\end{array}$ & $\begin{array}{l}\text { Power } \\
\text { Plant } \\
\text { capacity } \\
(\mathrm{kW})\end{array}$ \\
\hline
\end{tabular}




\begin{tabular}{lcccccccccc}
\hline Chanthaburi & $30,125.08$ & $6,025.02$ & $4,217.51$ & 12.50 & $52,718.89$ & $1,259.11$ & $2,928,827.11$ & $2,928.83$ & 0.418 & 417.93 \\
Rayong & $42,825.35$ & $8,565.07$ & $5,995.55$ & 12.50 & $74,944.36$ & $1,789.93$ & $4,163,575.48$ & $4,163.58$ & 0.594 & 594.12 \\
Chon Buri & $119,889.07$ & $23,977.81$ & $16,784.47$ & 12.50 & $209,805.88$ & $5,010.89$ & $11,655,882.17$ & $11,655.88$ & 1.663 & $1,663.23$ \\
Sa Kaeo & $236,444.30$ & $47,288.86$ & $33,102.20$ & 12.50 & $413,777.52$ & $9,882.43$ & $22,987,640.08$ & $22,987.64$ & 3.280 & $3,280.20$ \\
Chachoengsao & $99,436.79$ & $19,887.36$ & $13,921.15$ & 12.50 & $174,014.38$ & $4,156.06$ & $9,667,465.63$ & $9,667.47$ & 1.379 & $1,379.49$ \\
Prachin Buri & $107,280.05$ & $21,456.01$ & $15,019.21$ & 12.50 & $187,740.09$ & $4,483.88$ & $10,430,004.86$ & $10,430.00$ & 1.488 & $1,488.30$ \\
Tart & 2.71 & 0.54 & 0.38 & 12.50 & 4.74 & 0.11 & 263.22 & 0.26 & 0.000 & 0.04 \\
\hline
\end{tabular}

The cultivated area for cassava plantation in the Eastern region of Thailand is 2,447,321,979 Square kilometers or 1,529,576 acres, and it has yielded an average of 3.62 tons per acre over the past three years. The ratio of the cassava stalks production to biomass is at 0.112 of the 636,003 tons of cassava rhizomes planted per year in the Eastern region. Likewise, cassava stalks with the heating value of 14,591 kilojoules per kilogram $(\mathrm{kJ} / \mathrm{kg})$ of the whole eastern rhizome wastes, could generate $9.27 \times 10^{9} \mathrm{MJ}$ per year.

However, cassava stalks' production for fuel availability is highly essential, and also the dehumidifying of moisture content from $53.40 \%$ to $10.17 \%$, which represents an $80 \%$ weight loss according to the (Department of Energy, 2557). This loss that occurs from the method of collecting, processing, chopping, and drying of bars is equivalent to $30 \%$ (Department of Energy, 2557). The amount of biomass residues that could be used as fuel for electricity generation is given in Table 5. The potential energy production values at $\mathrm{Sa}$ Kaeo, Chachoengsao, Chon Buri, Rayong, Chanthaburi, Prachin Buri and Trat provinces are: $52,718.8974,944.36209,805.88$ 413,777.52 174.01. $187,740.094 .38$, and 4.74 MJ per year, equivalent of a renewable energy (oil) of 1,259.11 1,789.93 5,010.89 $9,882.434,156.064,483.880 .11$ toe.

\section{Conclusion}

There have been different biomass processing techniques for cassava wastes in recent years. However, our research centres on the analysis of a suitable processing biomass technique for generating electricity from cassava wastes in the eastern region of Thailand. Our case study focuses on the eastern region of Thailand, because it is the largest cassava cultivated area in Thailand. Our proposed technique and methods have produced some remarkable and outstanding results, which are highlighted in this section. Crop residual ratio (CRR) of cassava rhizome was 0.112 with the remaining amount of $636,003.35$ tons/year $(\sim 53.40 \%$ wb moisture content and $8.19 \mathrm{MJ} / \mathrm{kg}$ heating value). The estimated amount of cassava rhizome with chip/pellet grade of moisture content value of $\sim 10.17 \% \mathrm{wb}$, and heating value of $\sim 12.50 \mathrm{MJ} / \mathrm{Kg}$, is 89,040 tons/year, though the equivalent energy is $1,113.01 \mathrm{GJ}$ or $26.58 \mathrm{ktoe}$. These methodical results have shown that $61.8 \mathrm{GWh}$ of electricity could be generated to drive a plant of $8.8 \mathrm{MW}$.

The use of cassava wastes as an innovative and potential source of energy has opened up an interesting area of research. However, some measures and precautions should be prudently observed in order to avoid an unlikely occurrence of incrustation, due to the harmful characteristics of ashes from these wastes. In addition, a drying process technique must be adequately considered for the high moisture content present at the time of harvest, before these wastes are used for fuel production. Furthermore, a thorough evaluation of cassava production in other regions of Thailand is significantly necessary. Our study has provided right information on the agronomic, chemical, and physical characteristics of cassava wastes for energy generation. Wood, sugarcane bagasse, and ethanol represent different sources of energy production and consumption in Thailand; nevertheless, other modern forms of biomass should be encouraged and promoted [21]. The advancement of other forms will enhance a rapid development of sugarcane sector, and many industrial sectors with different sources of agricultural wastes for energy production and sustainability. Thereby reducing the level of uncertainty, that is associated with fossil-fuel market.

A rapid development of cassava wastes would strengthen its feasibility as another form of raw material for an integrated electricity generation, ethanol, and food production. This technique has been adopted by and used in the sugarcane sector of Brazil.

Our study has revealed and reinforced the versatile use of cassava crop for food, ethanol, and thermal energy. However, our study focuses on the promotion and use of rhizomes as a commercial generated biomass fuel. Though, there are other non-renewable fuels such as: crude oil and coal, however, cassava rhizomes serve as an alternative source of energy. In order words, it will help to limit the frequent shortage of commercial and industrial biomass fuels for the production of electricity and heat. Lastly, our future work will focus on how to enhance other potential agricultural wastes for energy generation

\section{References}

1. B. Ekasingh" C. Sungkapitux, J. Kitchaicharoen, and P. Suebpongsang, Competitive Commercial Agriculture in the Northeast of Thailand. A World Bank Research Publication, (2007)

2. Ministry of Commercem The export production from export structure of Thailand, (2009). [Online] Avaliable: http://www2.ops3.moc.go.thiexport!recode export! [20 July 2010]

3. Thailand Biomass Potential Study Report 2010, Department of Alternative Energy Development

4. Prakobboon N, Vahdati M. Review of the potential for cofiring of cassava rhizome for generating heat and power in cassava-based bio-ethanol plant in Thailand. International Journal of Biomass and Renewables ,2(2):14-22. (2013)

5. Punnarapong P, Promwungkwa A, Tippayawong N. Development and performance evaluation of a biomass 
gasification system for ceramic firing process. Energy Procedia ,110:53-58. (2017)

6. Jaroenkhasemmeesuk C, Tippayawong N. Technical and economic analysis of a biomass pyrolysis plant. Energy Procedia ,79: 950-955. (2015)

7. Tippayawong KY, Tippayawong N. Fuel recovery from thermal processing of post-consumer footwear waste. Energy Engineering,114(3):7-16 (2017)

8. Wongsiriamnuay $\mathrm{T}$, Tippayawong N. Effect of densification parameters on property of maize residue pellets. Biosystems Engineering ,139:111-120 (2015)

9. Malek K, de la Seigliere C, Fernandez C, Swaminathan M, Sebastian A, Arora D. Green coal: a new energy source from leaves. Energy Procedia,100 :484-491. (2016)

10. Pattiya A, Titiloye JO, Bridgwater A. Evaluation of catalytic pyrolysis of cassava rhizome by principal component analysis. Fuel,89:244-253. (2010)

11. The report on the agricultural economy of Thailand in 2017, Agricultural Information Center, Agricultural Economics Office

12. E1617-09 Standard Practice for Reporting Particle Size Characterization Data. Book of Standards Volume: 14.02.

13. ASTM E1755-01-Standard Test Method for Ash in Biomass. Book of Standards Volume: 11.06.

14. ASTM D2015-00 Standard Test Method for Gross Calorific Value of Coal and Coke by the Adiabatic Bomb Calorimeter.
15. APHA, American Public Health Association, Standard Methods for the Exam- ination of Water and Wastewater, Method 4500-Cl B, twentieth ed., Water Environment Federation, American Water Works Association, Washington DC, USA, (1999)

16. A. Pattyia, Thermochemical characterization of agricultural wastes from Thai cassava plantations, Energy Sources, Part A Recover. Util. Environ. Eff. 33 (8) (2011) 691e701, http://dx.doi.org/10.1080/15567030903228922.

17. E.D. Lavric, A.A. Konnov, J. De Ruyck, Dioxin levels in wood combustionda review, Biomass Bioenergy 26 (2) (2004) 115e145, http://dx.doi.org/10.1016/S09619534(03)00104-1.

18. I. Obernberger, T. Brunner, G. B€arnthaler, Chemical properties of solid bio-fuels significance and impact, Biomass Bioenergy 30 (11) (2006) 973-982 http://dx.doi.org/10.1016/j.biombioe.2006.06.011.

19. S. Arvelakis, H. Gehrmann, M. Beckman, E. Koukios, Studying the ash behav-iour of agricultural residues using thermal analysis, J. Therm. Analysis Calorim. 72 (2003) 1019-1030.

20. T.R. Miles, J.R. Miles, L.L. Baxter, R.W. Bryers, B.M. Jenkins, L.L. Oden, Boilerde posits from firing biomass fuels, Biomass Bioenergy 10 (2) (1996) 125e138, http://dx.doi.org/10.1016/0961-9534(95)00067-4.

21. J. Goldemberg, S.T. Coelho, Renewable energydtraditional biomass vs. mod- ern biomass, Energy Policy 32 (6) :711-714, (2004) 